\title{
Obtaining the Selected Surface Roughness by Means of Mathematical Model Based Parameter Optimization in Abrasive Waterjet Cutting
}

\author{
Andrzej Perec 1,2,* - Frank Pude1 - Michael Kaufeld ${ }^{3}$ - Konrad Wegener ${ }^{1,4}$ \\ 1ETH Zürich, Inspire AG, Switzerland \\ 2Jacob of Paradies University, Department of Technology, Poland \\ 3 University of Applied Sciences Ulm, Institute of Production Engineering and Materials Testing, Germany \\ ${ }^{4}$ ETH Zürich, Institute of Machine Tools and Manufacturing, Switzerland
}

The study on the effect of abrasive water jet machining process parameters on micro alloyed steel surface roughness was described. Taguchi method to predict machining parameters of due to minimum surface roughness was used. The influence of pressure, abrasive flow rate and traverse speed on the $R_{z}$ and $R_{\max }$ roughness parameters were presented. The optimum combination of processing parameters was established. Verified parameters were tested and the achieved results were compared to predicted values. This method allows limiting the amount of research needed to achieve the desired test results, thereby reducing the time as well as the cost required to carry them out. The Taguchi signal/noise $(\mathrm{S} / \mathrm{N})$ ratio enables the assessment of the relevance of the impact of various parameters on the process, which is still not well enough understood.

Keywords: abrasive water jet, design of experiment, optimization, cutting, prediction

\begin{abstract}
Highlights
- Influence of hydraulic pressure, traverse speed and abrasive flow rate on micro alloyed steel cut surface roughness was presented.

- An optimal set of parameters to achieve the smallest surface roughness of cut material was established.

- A significant reduction in the cost of the experimental work by reducing the number of necessary tests and shorten the time to carry out with high accuracy of results was achieved.
\end{abstract}

\section{O INTRODUCTION}

In recent years, high pressure water-jet machining has competed effectively with conventional methods of separation of materials. This is mainly because of the wide range of options it offers, including the processing of complex shapes, cutting of a large variety of materials, and its effectiveness under extreme conditions (hazard of fire or explosion, work under water up to a depth of $6000 \mathrm{~m}$, etc.) and the environmental friendliness [1].

Further advantages of the treatment of materials with a high-pressure fluid jet include:

- ability to cut with constant stand-off distance between the working nozzle and machined top surface of the workpieces,

- good surface structure after cutting or surface processing,

- leaves the structure of the cut material thermally unaffected,

- no internal stresses in the cutting zone,

- fluid jet can be operated very easily.

However, the application of a pure fluid jet is not very effective in cutting hard materials such as metals or rocks. The application of solutions for intensifying the erosive abilities of the fluid jet, such as the introduction of a loose abrasive is necessary for improving the effectiveness of the treatment. It should also be noted that the treatment is performed without significant increase in heat, as any heating produced as a result of the friction of the abrasive against the material and the nozzle is immediately counteracted by the water jet.

\section{WATER JET CUTTING}

Cutting by high-pressure water jet is an advanced method of separating materials. Processing materials using a high pressure abrasive water jet is more complex than conventional treatments. Existing models for predicting the results of cutting by water jet as presented for example in [2] to [4] cannot achieve satisfactory results in the wide area of parameter changes, especially for the large number of different materials. High pressure water is converted to a high speed jet inside a nozzle (Fig. 1a) and flows out of the nozzle at a speed of several hundred meters per second, hits a stream of abrasive particles and accelerates them to high particle speed. 


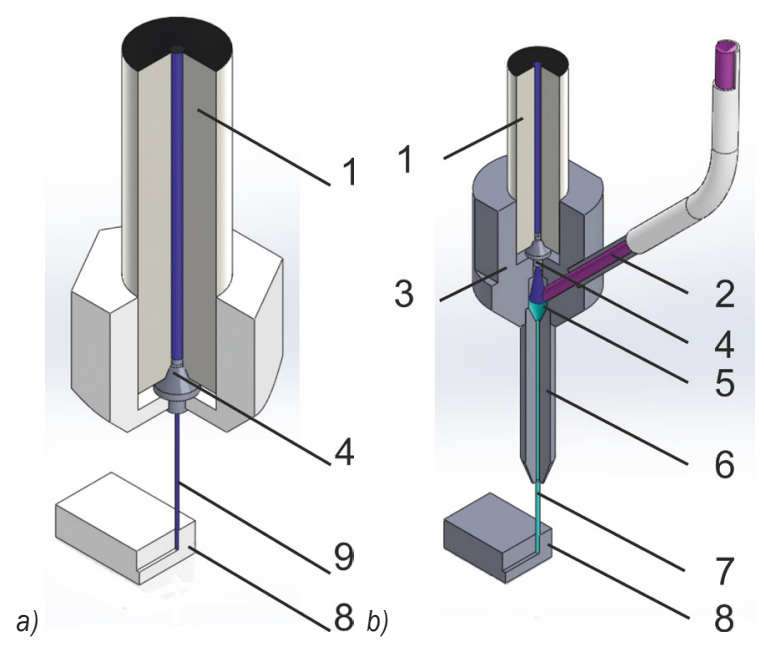

Fig. 1. Schematic diagram of: a) water jet cutting, and b) abrasive water jet cutting; 1. high pressure water inlet, 2. abrasive inlet, 3. cutting head, 4. water nozzle, 5. mixing chamber, 6. focussing tube, 7. high speed abrasive water Jet, 8. sample, 9. high speed water jet

Adding dry abrasive to the water jet in a special mixing chamber (Fig. 1b) increases cutting efficiency. As a result, it becomes possible to cut almost any material. Typical pressure levels used by the abrasive water jet (AWJ) system range from $400 \mathrm{MPa}$ to 600 $\mathrm{MPa}$. The most commonly used abrasive is garnet [3] and [5].

\section{MATERIALS AND EXPERIMENTAL SETUP}

The study is conducted on the test rig shown in Fig. 2 by using a high pressure intensifier (BYPUMP 50APC) presented in Fig. 2b. The maximum working pressure is $400 \mathrm{MPa}$ at a flow rate of $5 \mathrm{dm}^{3} / \mathrm{min}$. This allows the use of a water nozzle with maximum diameter of $0.4 \mathrm{~mm}$.

The cutting head used, as shown in Fig. 2a is equipped with a water nozzle with a diameter of 0.28 $\mathrm{mm}$, and a focussing tube with a diameter of $0.76 \mathrm{~mm}$ and a length of $75 \mathrm{~mm}$, mounted on 3-axis Siemens Sinumerik 840D CNC machine as can be seen in Fig. 2c.

The working area is $1000 \mathrm{~mm} \times 1000 \mathrm{~mm} \times 400 \mathrm{~mm}$. The machine is equipped with an abrasive feeder from the Swiss company Allfi. During the test garnet (Almandine) 80 mesh is used, from which a sample is presented in Fig. 3. The basic properties of this abrasive are presented in Table 1.

The garnet abrasive group contains closely related, isomorphous, minerals that may contain low percentages of elements found in other members of
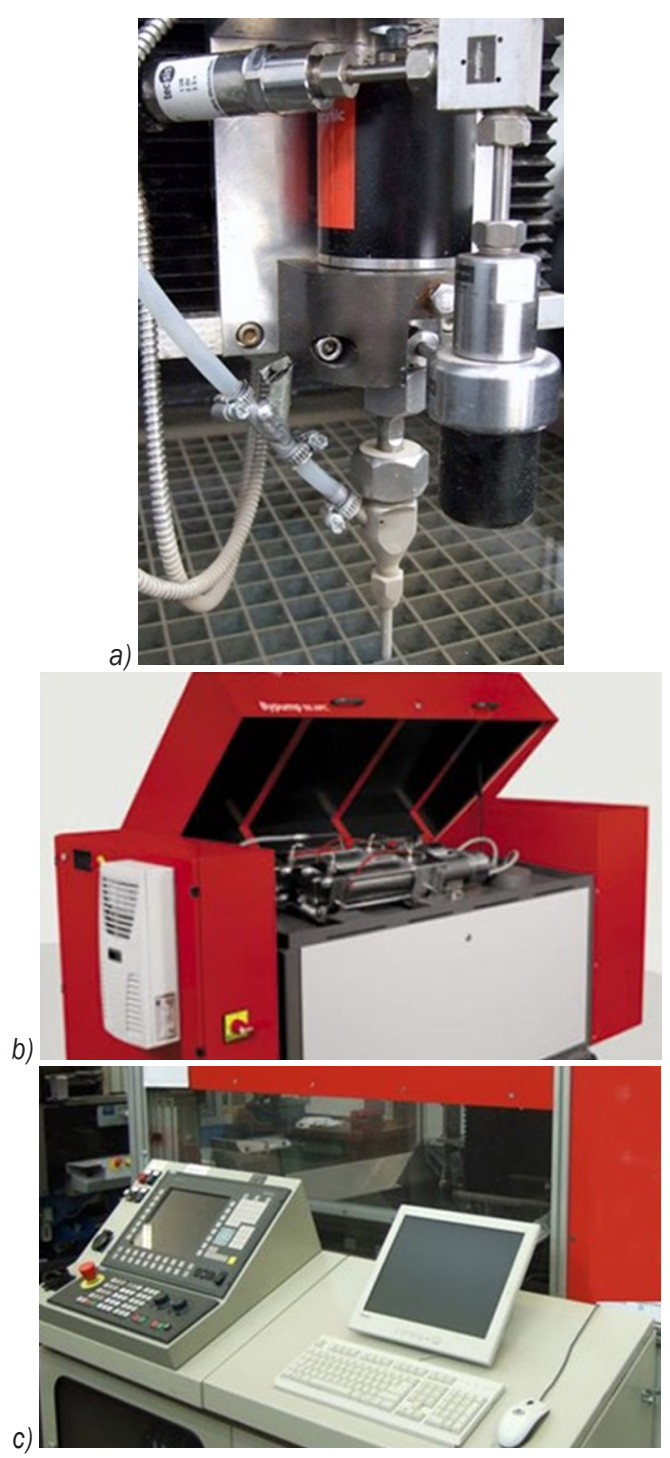

Fig. 2. Test rig: a) cutting head, b) high pressure intensifier, and c) control module

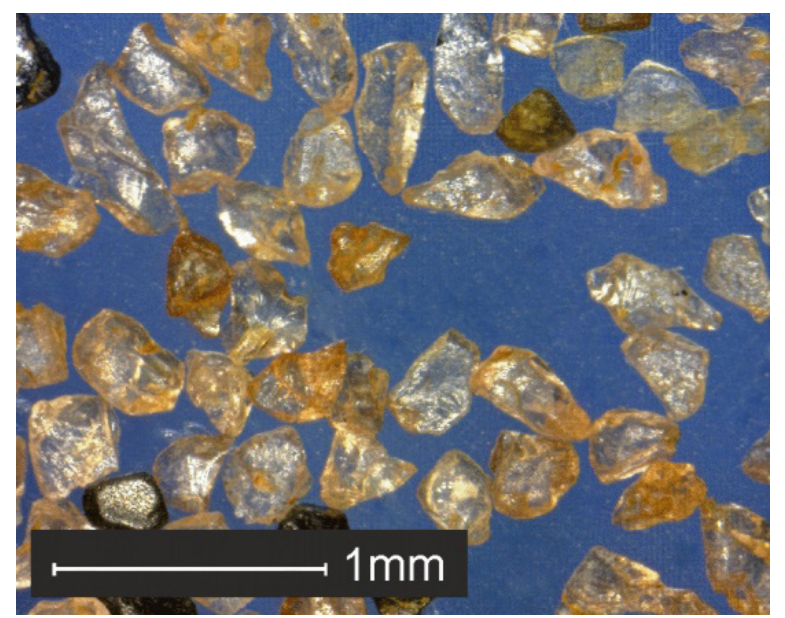

Fig. 3. Garnet (Almandine) 80 mesh 
the garnet family. Garnets are isostructural, meaning that they share the same crystal structure [6].

Table 1. Garnet (Almandine) properties [6]

\begin{tabular}{ll}
\hline Crystal system & Cubic \\
\hline Twinning & None \\
\hline Unit cell & $a=11.53 \AA$ \\
\hline Habit & $\begin{array}{l}\text { crystals usually dodecahedrons or } \\
\text { trapezohedrons; also in combination or with } \\
\text { hexoctahedron; massive; granular }\end{array}$ \\
\hline Cleavage & $1 ;\{110\}$ parting sometimes distinct \\
\hline Fracture & conchoidal to uneven \\
\hline Tenacity & Brittle \\
\hline Color & $\begin{array}{l}\text { deep red to reddish-brown, some-times with a } \\
\text { violet or brown or brownish black hue }\end{array}$ \\
\hline Hardness (Mohs) & 6.5 to 7.5 \\
\hline Density & 4.1 to 4.3 \\
\hline
\end{tabular}

As sample used micro alloyed steel 27MnSiVS6 (DIN 1.5232). It is ferritic-perlitic high strength Mn-V-based, low alloy high grade steel with good machinability for controlled cooling from working heat steel for precipitation hardening.

\section{THE TAGUCHI METHOD}

The selection of parameters which can produce optimal results is usually a complex process. Typically this requires carrying out a number of tests, and in this way the effect of technological parameters on the properties of the final product can be determined. The Design of Experiment can be shortened by using this method. The planning of such studies is an interdisciplinary science, which lies at the intersection of metrology, applied mathematics, statistics, and computer science, allowing researchers to use the information the program has provided them with to reduce both the cost and time expended in obtaining the relevant information. This Design of Experiment enables researchers to select the input variables which significantly affect the process observed and can also build a mathematical model of the process and the mathematical relationships between input and output values. Further, it can determine the value of the input quantities which affect the most desired outcome of the process (process optimization), and determine the effect of variation in the size of the input on the variability of the whole process [7].

The Taguchi Method [8] is a technique that provides a systematic and efficient methodology for process optimization and is a useful tool for the design of high quality systems. The Taguchi approach to Design of Experiments is easy for users with less experience of statistical methods to apply, and has therefore gained wide popularity in engineering. It is used for example in surface engineering [9] and [10], turning [11], and of course in water jet machining [12].

Abrasive water jet machining allows for the cutting of almost any material with high efficiency and accuracy. Therefore Taguchi approach is successfully used in the cutting optimization of a different materials such as coal [13], ceramics [14], [15], aramid [16] and glass/epoxy composite [17], inconel [18] and aluminum [19] to [21]. The well-studied material is only mild steel [22] and stainless steel [12] and [23]. Micro-alloyed steel used in test is significantly different from mild and stainless steel, it is advisable to carry out appropriate roughness tests.

The average roughness $\left(R_{\mathrm{a}}\right)$ measurements for machined surface finishes have become the standard default representation for abrasive waterjet machined surfaces. By comparison the relative differences between $R_{\mathrm{a}}$ and $R_{\mathrm{z}}$ surfaces, it was demonstrated that $R_{\mathrm{z}}$ measurements provide a more accurate representation of the surface finish of an abrasive waterjet machined surface [24]. Therefore, the novelty of their research also applies to the use of other $\left(R_{\mathrm{z}}\right.$ and $R_{\max }$ ) roughness parameters, than commonly used $R_{\mathrm{a}}$.

The Taguchi Method is an engineering methodology for obtaining optimized products and processes, which are minimally robust and which produce high-quality products with reduced development and production costs. Signal to noise ratio ( $\mathrm{S} / \mathrm{N}$ ratio) and orthogonal matrix are two major tools used in the planning of experiments.

The $\mathrm{S} / \mathrm{N}$ ratio values can be divided into three categories when the number is continuous:

- nominal is the best,

- smaller is better,

- larger is better.

The Taguchi Method is used to generate a $\mathrm{S} / \mathrm{N}$ ratio $\eta$ in order to determine the current scatter of values. The signal $(\mathrm{S})$ is derived from factors which are adjustable or under the control of the user, but noise $(\mathrm{N})$ refers to those factors which affect the signal, but which are beyond the control of the user.

The aim of the design is to enable the selection of the parameters of the experiment (in this case the process), so as to maximize the $\eta$. Various $\mathrm{S} / \mathrm{N}$ indicators can be used according to the researcher's needs [10]. Taguchi analysis observes the higher value of mean $\mathrm{S} / \mathrm{N}$ ratio as better quality characteristic.

Orthogonal matrix is selected subset of combinations of multiple factors at multiple levels. Taguchi Orthogonal matrix are balanced to ensure that 
all levels of all factors are considered equally. For this reason, the factors can be evaluated independently of each other despite the fractionality of the design [25].

In abrasive water jet cutting typically aims at achieving the maximal depth of cut and low roughness of the cut surface. Especially during precision cutting low roughness of the cut surface is of paramount importance. In this case the roughness of the kerf's surface should be as small as possible. This is described by the "smaller is better" equation:

$$
\eta=-10 \log \left(\frac{1}{n} \sum_{i=1}^{n} y_{i}^{2}\right)
$$

where $n$ is the number of repetitions of measurement, $y$ the current value of the measurement, and $i$ the number of variables.

\section{OPTIMIZATION AND PREDICTION PROCEDURE}

The influence of the selected parameters of abrasive water jet cutting on the accepted optimization criterion - surface roughness of the cutting kerf - is analyzed.

A machining parameter selection process, using the L18 orthogonal array, was applied in this study (Table 2). This array is chosen because it consists of three control parameters: one (P1) with 6 levels, and the next two (P2 and P3) with three levels, as shown in Table 2.

Table 2. Orthogonal array L18 for Taguchi design

\begin{tabular}{cccc}
\hline Test number & P1 & P2 & P3 \\
\hline 1 & 1 & 1 & 1 \\
\hline 2 & 1 & 2 & 2 \\
\hline 3 & 1 & 3 & 3 \\
\hline 4 & 2 & 1 & 1 \\
\hline 5 & 2 & 2 & 2 \\
\hline 6 & 2 & 3 & 3 \\
\hline 7 & 3 & 1 & 2 \\
\hline 8 & 3 & 2 & 3 \\
\hline 9 & 3 & 3 & 1 \\
\hline 10 & 4 & 1 & 3 \\
\hline 11 & 4 & 2 & 1 \\
\hline 12 & 4 & 3 & 2 \\
\hline 13 & 5 & 1 & 2 \\
\hline 14 & 5 & 2 & 3 \\
\hline 15 & 5 & 3 & 1 \\
\hline 16 & 6 & 1 & 3 \\
\hline 17 & 6 & 2 & 1 \\
\hline 18 & 6 & 3 & 2 \\
\hline
\end{tabular}

In this case, the control parameter P1 is represented by the traverse speed, control parameter $\mathrm{P} 2$ by the pressure, while control parameter $\mathrm{P} 3$ by the abrasive flow rate.

The Minitab16 program is used for the calculation procedure. The variation interval of the selected cutting parameters used under optimization are presented in Table 3 .

After conducting research at relevant parameters according to Taguchi array, roughness values were measured for each parameter combination.

Roughness was measured according to the most commonly used methods: $R_{\max }$, and $R_{\mathrm{z}}$ [26] to [28].

Roughness measurements were performed on optical 3D measuring system NanoFocus mSurf (Fig. 4a).

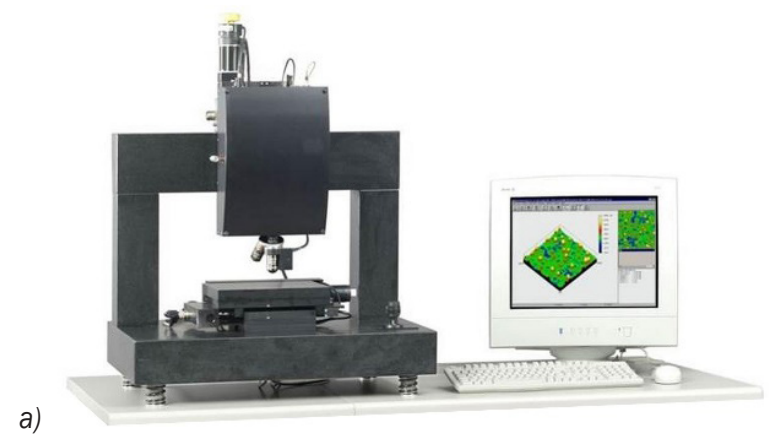

b)

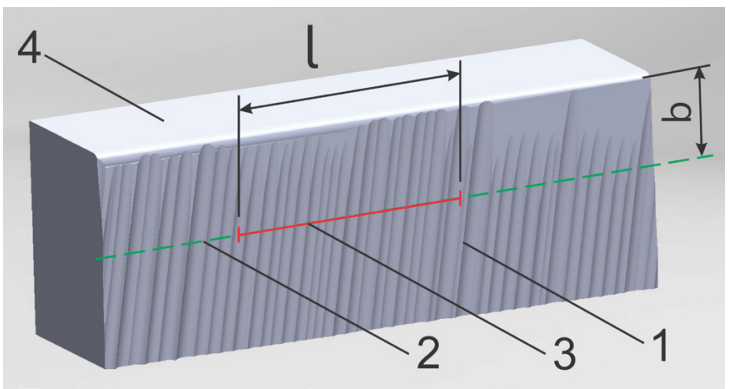

Fig. 4. Measurement of roughness: a) NanoFocus msurf optical $3 D$ measuring system, and b) details of measurement: 1 cutting surface, 2 sampling line, 3 sampling length, and ) top plane

The measurement principle is based on the white light confocal technique and is specially designed for quality control of technical surfaces as a completely independent $3 \mathrm{D}$ video measurement system, with cutoff wave length $l_{\mathrm{c}}$ filter, according to DIN EN ISO 4287 norm.

Optical system msurf allowed representation of 3D structures in the nanometer range, measurement of surfaces, microstructures and surface topographies on working area: $X=380 \mathrm{~mm}, Y=250 \mathrm{~mm}$ and $Z=355$ $\mathrm{mm}$. 
To eliminate the influence of rounded cutting edges (Fig. 4b), the sampling line was set at $b=1$ $\mathrm{mm}$ from the top surface. The sampling length of the measurement is $l=4 \mathrm{~mm}$. Each measurement of the roughness was taken five times and their arithmetic mean was calculated as to minimize the errors.

Fig. 5 presents the calculated dependency terms of the cut of the value of $\mathrm{S} / \mathrm{N}$ ratios, $R_{\mathrm{z}}$ and $R_{\max }$ coefficients. The higher the signal to noise ratio, the more favorable is the effect of the input variable on the output. The impact of individual process parameters on the $\mathrm{S} / \mathrm{N}$ ratio is similar for all analyzed roughness values. For each roughness coefficient, a maximal S/N ratio is reached at the smallest traverse speed value, which was $20 \mathrm{~mm} / \mathrm{min}$.

In the case of pressure, the largest value of the $\mathrm{S} / \mathrm{N}$ ratio is reached at the highest pressure, which was $360 \mathrm{MPa}$. This result is obtained for all roughness coefficients. Maximal $\mathrm{S} / \mathrm{N}$ ratio values are reached for the highest abrasive flow rate $(100 \mathrm{~g} / \mathrm{min})$, for all roughness coefficients. By increasing the kinetic energy of the abrasive water jet a lower level of surface quality at the bottom of the cutting edge can be transferred to better quality levels.
Table 3. Parameters of the cutting process and values of $\eta$ factor

\begin{tabular}{ccccccc}
\hline $\begin{array}{c}\text { Traverse } \\
\text { speed }\end{array}$ & Pressure & $\begin{array}{c}\text { Abrasive } \\
\text { flow rate }\end{array}$ & $R_{\max }$ & $\begin{array}{c}\mathrm{S} / \mathrm{N} \\
\left(R_{\max }\right)\end{array}$ & $R_{\mathrm{z}}$ & $\mathrm{S} / \mathrm{N}\left(R_{\mathrm{z}}\right)$ \\
\hline$[\mathrm{mm} / \mathrm{min}]$ & {$[\mathrm{MPa}]$} & {$[\mathrm{g} / \mathrm{min}]$} & {$[\mathrm{mm}]$} & $\eta$ & {$[\mathrm{mm}]$} & $\eta$ \\
\hline 20 & 360 & 100 & 15.59 & -24.67 & 13.61 & -22.68 \\
\hline 20 & 300 & 80 & 17.44 & -24.29 & 14.43 & -23.19 \\
\hline 20 & 240 & 60 & 19.32 & -26.24 & 18.33 & -25.26 \\
\hline 40 & 360 & 100 & 21.02 & -27.10 & 12.76 & -22.12 \\
\hline 40 & 300 & 80 & 18.41 & -25.22 & 15.67 & -23.90 \\
\hline 40 & 240 & 60 & 15.39 & -26.55 & 14.49 & -23.22 \\
\hline 60 & 360 & 80 & 22.78 & -25.09 & 19.52 & -25.81 \\
\hline 60 & 300 & 60 & 25.56 & -28.45 & 20.46 & -26.22 \\
\hline 60 & 240 & 100 & 19.18 & -27.47 & 16.38 & -24.29 \\
\hline 100 & 360 & 60 & 20.37 & -25.28 & 17.51 & -24.87 \\
\hline 100 & 300 & 100 & 18.09 & -26.64 & 14.69 & -23.34 \\
\hline 100 & 240 & 80 & 19.43 & -26.29 & 17.39 & -24.81 \\
\hline 140 & 360 & 80 & 21.82 & -26.67 & 16.66 & -24.43 \\
\hline 140 & 300 & 60 & 31.76 & -27.00 & 19.40 & -25.76 \\
\hline 140 & 240 & 100 & 29.25 & -29.17 & 20.47 & -26.22 \\
\hline 180 & 360 & 60 & 22.04 & -26.45 & 19.65 & -25.87 \\
\hline 180 & 300 & 100 & 21.47 & -27.02 & 17.76 & -24.99 \\
\hline 180 & 240 & 80 & 24.33 & -27.05 & 20.45 & -26.21 \\
\hline & & & & & &
\end{tabular}

The effect of control factors were investigated through the analysis of variance - ANOVA. Based on

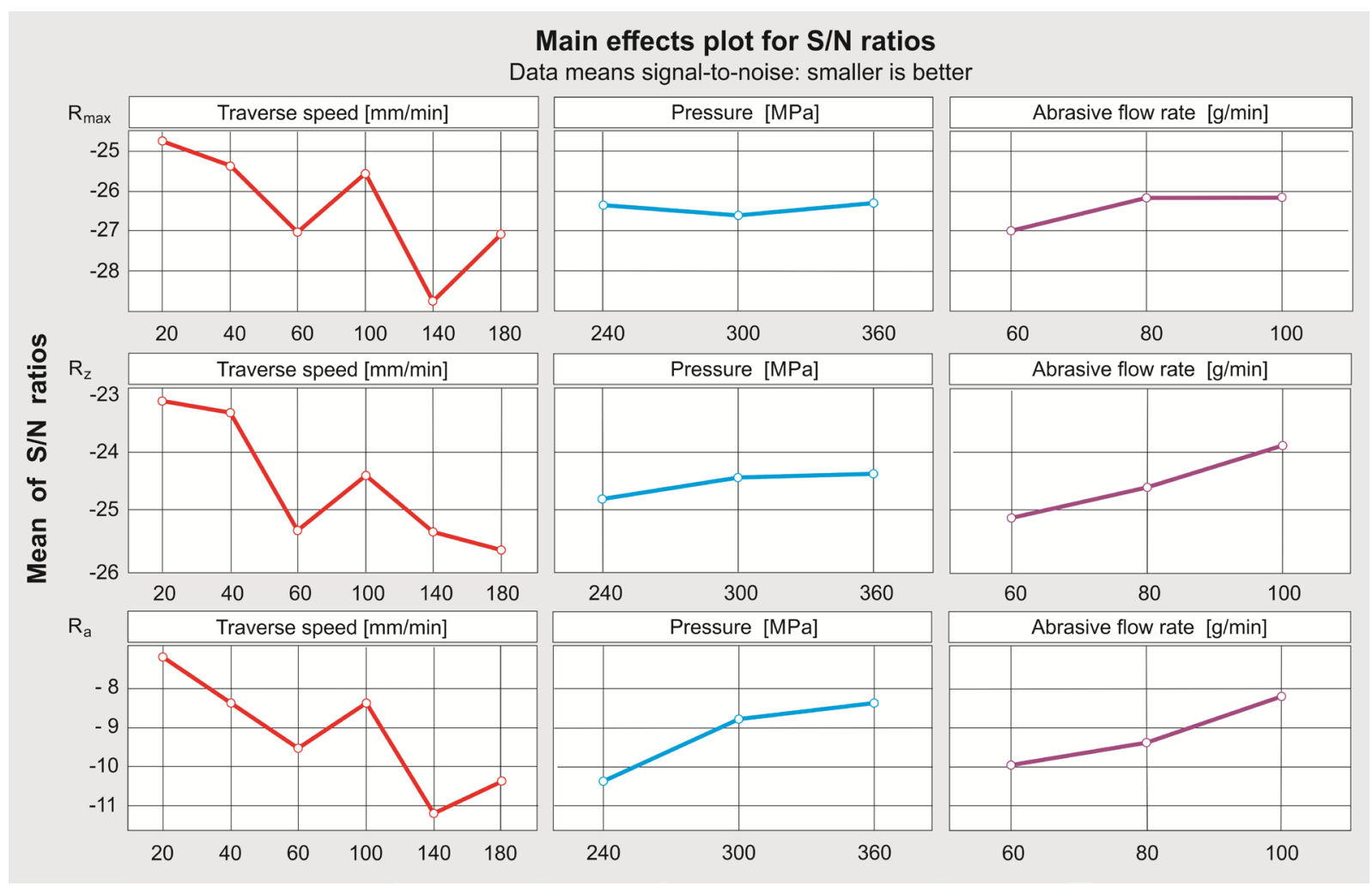

Fig. 5. S/N ratio of roughness for each of tested parameters 
the results shown in Table 3, test the significance of machining parameters: traverse speed, pressure and abrasive flow rate on $R_{\max }$ and $R_{\mathrm{z}}$ surface roughness parameters was calculated.

Table 4. ANOVA and F-ratio for $R_{\max }$

\begin{tabular}{lccccc}
\hline Parameter & $S S$ & $D f$ & $M s$ & $F$ & $p$ \\
\hline Traverse speed & 70.307 & 5 & 14.061 & 3.189 & 0.071 \\
\hline Pressure & 28.968 & 2 & 14.484 & 3.285 & 0.091 \\
\hline $\begin{array}{l}\text { Abrasive flow } \\
\text { rate }\end{array}$ & 30.441 & 2 & 15.220 & 3.452 & 0.083 \\
\hline Error & 35.270 & 8 & 4.409 & & \\
\hline
\end{tabular}

$S S$ is sum of squares, $D f$ degree of freedom, Ms mean square, and $F$ ratio of variance of a source to variance of error.

The results of machining parameters influence on $R_{\max }$ shows Table 4 and on $R_{\mathrm{z}}$ shows Table 5 .

This analysis was carried out for a $95 \%$ confidence level. It was found that traverse speed failed the test of significance at $95 \%$ confidence level and therefore, they were pooled [29]. The factors that pass the test of significance are considered significant. They are considered insignificant if they fail the test of significance and are usually treated as if they are not present. This process is called pooling.

Pressure is the most significant factor influencing the assessment of both $R_{\max }$ and $R_{\mathrm{z}}$. Meanwhile abrasive flow rate respectively have sub significant effect on both $R_{\max }$ and $R_{\mathrm{z}}$. Traverse speed is the least significant in influencing both $R_{\max }$ and $R_{z}$.

Table 5. ANOVA and F-ratio for $R_{z}$

\begin{tabular}{lccccc}
\hline Parameter & $S S$ & $D f$ & $M s$ & $F$ & $p$ \\
\hline Traverse speed & 27.763 & 5 & 5.553 & 2.609 & 0.111 \\
\hline Pressure & 8.496 & 2 & 4.248 & 1.996 & 0.198 \\
\hline $\begin{array}{l}\text { Abrasive flow } \\
\text { rate }\end{array}$ & 10.114 & 2 & 5.057 & 2.376 & 0.155 \\
\hline Error & 17.028 & 8 & 2.129 & & \\
\hline
\end{tabular}

$S S$ is sum of squares, $D f$ degree of freedom, Ms mean square, and $F$ ratio of variance of a source to variance of error.

In Fig. 6 are shown the predicted and the measured roughness values reached at optimal cutting parameters: traverse speed $=20 \mathrm{~mm} / \mathrm{min}$, pressure $=360 \mathrm{MPa}$ and abrasive flow rate $=80 \mathrm{~g} / \mathrm{min}$. The best prediction data is reached for the roughness coefficient $R_{\max }$. and the worst fit is reached for the roughness coefficient $R_{z}$.

Fig. 7 shows an exemplary photorealistic shading view and profile generated by machining parameters which were optimal from the roughness point of view. It is possible to observe parallel machining traces characteristic for abrasive grain cutting.

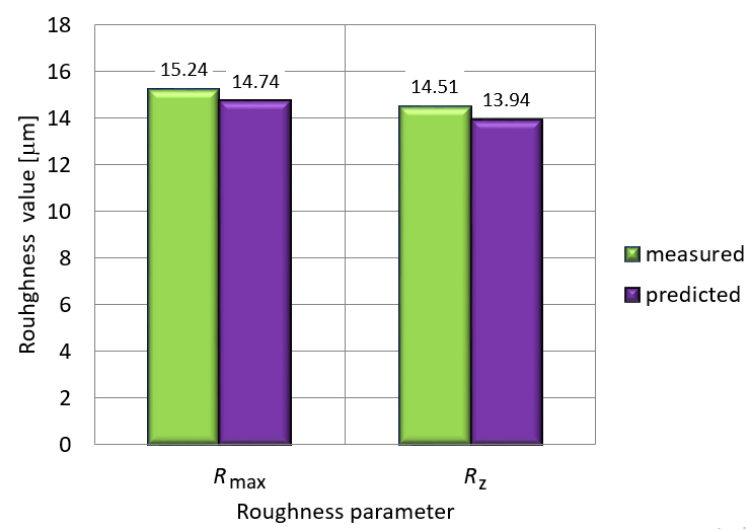

Fig. 6. Results of predicted and measured values for different roughness parameters
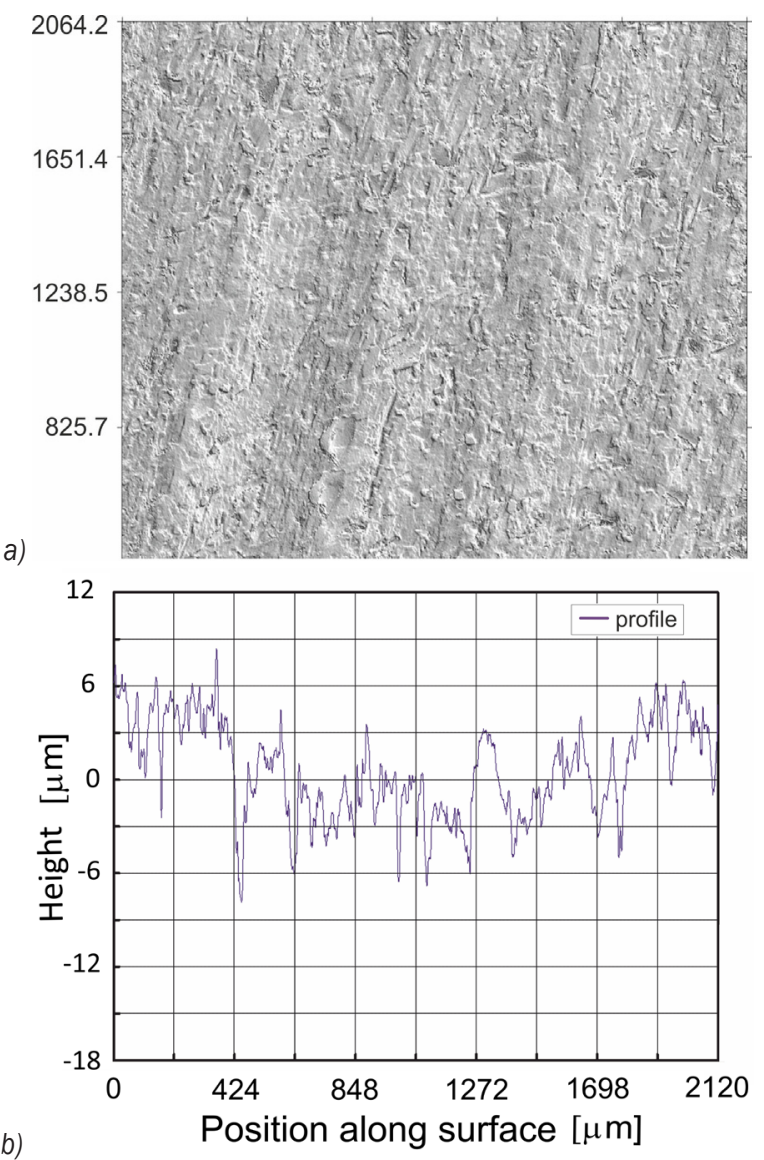

Fig. 7. Sample of a cut steel surface at optimal parameters: traverse speed $=20 \mathrm{~mm} / \mathrm{min}$, pressure $=360 \mathrm{MPa}$, abrasive flow rate $=100 \mathrm{~g} / \mathrm{min}$, a) photorealistic shading view, b) surface profile of the sample 


\section{CONCLUSIONS}

On the basis of experimental results, calculation of $\mathrm{S} / \mathrm{N}$ ratios and confirmation results of tested steel by Abrasive Water Jet the following conclusions can be drawn as follows:

1. Pressure is the most significant control factor on both surface roughness values $R_{\max }$ and $R_{z}$ generated by AWJ machining.

2. Abrasive flow rate is a sub significant machining parameter in influencing both $R_{\max }$ and $R_{z}$ surface roughness values.

3. Traverse speed is the least significant machining parameter in influencing on both $R_{\max }$ and $R_{z}$ surface roughness values.

4. Increasing the hydraulic pressure results in lower $R_{\max }$ and $R_{z}$ roughness values.

5. Traverse speed shows the opposite effect on both $R_{\max }$ and $R_{z}$ roughness values.

6. By increasing the kinetic energy of the abrasive water jet a lower level of surface quality at the bottom of the cutting edge can be transferred to better quality levels.

7. Taguchi method turns out to be a suitable method for design and analysis of experiments. Reachable surface roughness values for the predicted optimal machining parameters are similar (differences are smaller than $4 \%$ ) than the surface roughness values obtained in experiments defined in the orthogonal array.

8. For optimum surface roughness abrasive water jet machining combination parameters is:

- pressure $=360 \mathrm{MPa}$,

- abrasive flow rate $=80 \mathrm{~g} / \mathrm{min}$,

- $\quad$ traverse speed $=20 \mathrm{~mm} / \mathrm{min}$.

The method may be particularly useful in planning research into the treatment of new materials regarding which there is insufficient information, about the properties. It may also be important in assessing the significance of the parameters that influence the cutting of new materials and newly developed procedures which are not yet sufficiently understood.

\section{REFERENCES}

[1] Kukiełka, K. (2016). Ecological aspects of the implementation of new technologies processing for machinery parts. Annual Set the Environmental Protection, vol. 18, no. 1, p. 137-157.

[2] Feed Rate Calculator (2017). From http://www.wardjet.com/ downloads.html accessed on 17-01-2017.

[3] Perec, A., Pude, F., Stirnimann, J., Wegener, K. (2015). Feasibility study on the use of the fractal analysis method for evaluating the surface quality generated by high pressure waterjet machining. Tehnički vjesnik - Technical Gazette, vol. 22, no. 4, 879-883, D0I:10.17559/TV-20140128231244.

[4] Strnadel, B., Hlaváč, L., Gembalová, L. (2013). Effect of steel structure on the declination angle in AWJ cutting. International Journal of Machine Tools and Manufacture, vol. 64, p. 12-19, D0l:10.1016/j.jijmachtools.2012.07.015.

[5] Valíček, J., Harničárová, M., Hlavatý, I., Grznárik, R., Kušnerová, M., Hutyrová, Z., Panda, A. (2016). A new approach for the determination of technological parameters for hydroabrasive cutting of materials. Materialwissenschaft und Werkstoff-technik, vol. 47, no. 5-6, p. 462-471, D0l:10.1002/ mawe.201600522.

[6] Martinec, P., Foldyna, J., Sitek, L., Ščučka, J. Vašek, J. (2002). Abrasives for AWJ Cutting. Institute of Geonics, Ostrava.

[7] Perec, A., Ťavodova, M. (2016). Abrasive water jet cutting depth optimization by taguchi approach. Manufacturing Technology, vol. 16, no. 3, p. 590-595, Dol:10.1016/j.proeng.2016.06.680.

[8] Taguchi, G. (1989). Quality Engineering in Production Systems. McGraw-Hill, New York.

[9] Macodiyo, D.O., Soyama, H. (2006). Optimization of cavitation peening parameters for fatigue performance of carburized steel using Taguchi methods. Journal of Materials Processing Technology, vol. 178, no. 1-3, p. 234-240, D0l:10.1016/j. jmatprotec.2006.03.172.

[10] Olik, R., Warcholinski, B., Ratajski, J., Michalski, J. (2011). Application of Taguchi Method to Optimize process Parameters of Gas Nitriding. Surface Engineering, vol 4, p. 3-7.

[11] Krishankant, J.T., Bector, M., Kumar R. (2012). Application of Taguchi method for optimizing turning process by the effects of machining parameters. International Journal of Engineering and Advanced Technology, vol. 2, no. 1, p. 263-274.

[12] Badgujar, P.P., Rathi, M.G. (2014). Taguchi method implementation in abrasive waterjet machining process optimization. International Journal of Engineering and Advanced Technology, vol. 3, no. 5, p. 66-70.

[13] Sharma, V., Chattopadhyaya, S.A., Hloch, S. (2011). Multi response optimization of process parameters based on Taguchi-Fuzzy model for coal cutting by water jet technology. International Journal of Advanced Manufacturing Technology, vol. 56, no. 9-12, p. 1019-1025, D0l:10.1007/s00170-0113258-x.

[14] Santhanakumar, M., Adalarasan, R., Rajmohan, M. (2015). Experimental modelling and analysis in abrasive waterjet cutting of ceramic tiles using grey-based response surface methodology. Arabian Journal for Science \& Engineering, vol. 40, no. 11, p. 3299-3311, D0l:10.1007/s13369-015-1775-x.

[15] Srikanth, D.V., Sreenivasa, Rao, M.S. (2015). Application of Taguchi \& response surface methodology in optimization for machining of ceramics with abrasive jet machining. Materials Today: Proceedings, vol. 2, no. 4-5, p. 3308-3317, D0I:10.1016/J.matpr.2015.07.149.

[16] Azmir, M.A., Ahsan, A.K., Rahmah, A. (2009). Effect of abrasive water jet machining parameters on aramid fibre reinforced plastics composite. International Journal of Material Forming, vol. 2, no 1, p. 3744, Dol:10.1007/s12289-008-0388-2.

[17] Azmir, M.A., Ahsan, A.K. (2008). Investigation on glass/epoxy composite surfaces machined by abrasive water jet machining. 
Journal of Materials Processing Technology, vol. 198, no. 1-3, p. 122-128, D0I:10.1016/j.jmatprotec.2007.07.014.

[18] Yünlü, L., Çolak, O., Kurbanoglu, C. (2014). Taguchi DOE analysis of surface integrity for high pressure jet assisted machining of Inconel 718. Procedia CIRP, vol. 13, p. 333-338, D0l:10.1016/j.procir.2014.04.056.

[19] Kolahan, F., Khajavi, H. (2009). Modeling and optimization of abrasive waterjet parameters using regression analysis. International Journal of Mechanical, Industrial, Mechatronic and Manufacturing Engineering, vol. 3, no. 11 p. 1425-1430.

[20] Nagdeve, L., Chaturvedi, V., Vimal, J. (2012). Implementation of Taguchi approach for optimisation of abrasive water jet machining. International Journal of Instrumentation, Control and Automation, vol. 1, no. 3-4, p. 9-13.

[21] Shukla, R, Singh, D. (2017). Experimentation investigation of abrasive water jet machining parameters using Taguchi and Evolutionary optimization techniques. Swarm and Evolutionary Computation, vol. 32 p. 167-183, D0I:10.1016/j. swevo.2016.07.002.

[22] Rao, M.S., Ravinder, S., Kumar, A.S. (2014). Parametric optimization of abrasive waterjet machining for mild steel: Taguchi approach. International Journal of Current Engineering and Technology, no. 2, p. 28-30, Dol:10.14741/ ijcet/spl.2.2014.06.

[23] Ramprasad, Upadhyay, G., Hassan, K. (2015). Optimization MRR of stainless steel 403 in abrasive water jet machining using Anova and Taguchi method. Journal of Engineering Research and Applications, vol. 5, no. 5, p. 86-91.

[24] Miles, P., Henning, A. (2013) Rz: A better measurement of abrasive waterjet cut surface finishes. WJTA-IMCA Conference Proceedings. Houston, paper C2.

[25] Weibull Reliability Hot Wire from http://www.weibull.com/ hotwire/issue111/tooltips111.htm accessed on 16-01-2017.

[26] Hreha, P., Hloch, S. (2013). Potential use of vibration for metrology and detection of surface topography created by abrasive waterjet. International Journal of Surface Science and Engineering, vol. 7, no. 2, p. 135-150, Dol:10.1504/ IJSURFSE.2013.053699.

[27] Perec, A. (2016). Abrasive suspension water jet cutting optimization using orthogonal array design. Procedia Engineering, vol. 149, p. 366-373, D0l:10.1016/j. proeng.2016.06.680.

[28] Suszynski, Z., Majchrzak, P., Musial, W. (2005). Detection and analysis of subsurface cracks in ground ceramics using thermal wave method. 34th Winter School on Wave and Quantum Acoustics. Journal de Physique IV Proceedings, vol. 129, p. 275-279, D0l:10.1051/.jp4:2005129056.

[29] Roy, R.K. (2001). Design of Experiments Using the Taguchi Approach: 16 Steps to Product and Process Improvement. John Wiley \& Sons Inc., New York. 